\title{
COMPARING THE EFFECTIVENESS OF POSTERIOR CORD STIMULATION WITH MEDIAL CORD STIMULATION IN INFRACLAVICULAR BLOCK FOR FOREARM AND HAND SURGERIES USING NERVE STIMULATOR- A RANDOMISED CONTROLLED TRIAL
}

\author{
Loganathan $S^{1}$, Karthick Raja $A^{2}$ \\ ${ }^{1}$ Senior Assistant Professor, Department of Anaesthesiology, Government Theni Medical College, Theni, Tamilnadu. \\ ${ }^{2}$ Assistant Professor, Department of Anaesthesiology, Government Theni Medical College, Theni, Tamilnadu.
}

ABSTRACT

\section{BACKGROUND}

Peripheral nerve block remains a well-accepted component of comprehensive anaesthetic care and has extended role of analgesia and chronic pain management. Numerous modifications in techniques of infraclavicular brachial plexus block have been developed to improve success rate and decrease risk of complications.

The aim of the study is to compare the effectiveness of blocking by stimulating posterior cord with the medial cord in infraclavicular block for forearm and hand surgeries using hand stimulator.

\section{MATERIALS AND METHODS}

This randomised control trial included 62 patients of ASA I/II of either sex undergoing surgeries on elbow, forearm, hand. Patients were randomly allocated into two groups $\mathrm{P}$ and $\mathrm{M}$, where the stimulation of posterior and medial cords are done respectively and effectiveness of sensory and motor components of upper limb block were assessed.

\section{RESULTS}

The age, weight, gender, duration of surgery and surgical distribution and demographic profile were comparable in two groups. Sensory block in median/ulnar nerve with a p value of 0.718 is statistically insignificant in two groups. Sensory block of musculocutaneous nerve with $\mathrm{P}$ value of 0.001 is statistically significant, Sensory block of radial nerve with $\mathrm{P}$ value of 0.001 is statistically significant. Motor block in wrist with $93.5 \%$ in group $\mathrm{P}$ and $87.1 \%$ in group $\mathrm{M}$ is statistically insignificant (P-0.390). Motor block in elbow in group $\mathrm{P}$ is $96.8 \%$, in group $\mathrm{M}$ is $45.2 \%$ and with $\mathrm{P}$ value of 0.001 is statistically significant. Complete sensory block in all 4 nerves is more with P group and is statistically significant (P 0.001). Complete motor block in all 3 joints is better in group $\mathrm{P}$ and is statistically significant (P 0.001). Effectiveness of surgical block with a $\mathrm{P}$ value of 0.002 is significant. Complication between two groups is not significant.

\section{CONCLUSION}

From this study, it is inferred that nerve stimulator-guided posterior cord stimulation in infraclavicular block through coracoid approach has greatest extent and effectiveness of sensory/motor blockade compared to medial cord stimulation with similar rate of complications.

\section{KEYWORDS}

Infraclavicular Brachial Plexus Block, Motor and Sensory Block, Medial Cord and Posterior Cord, Ulnar Nerve, Median Nerve, Musculocutaneous Nerve, Radial Nerve.

HOW TO CITE THIS ARTICLE: Loganathan S, Raja KA. Comparing the effectiveness of posterior cord stimulation with medial cord stimulation in infraclavicular block for forearm and hand surgeries using nerve stimulator- A randomised controlled trial. J. Evolution Med. Dent. Sci. 2017;6(45):3554-3558, DOI: 10.14260/Jemds/2017/765

\section{BACKGROUND \\ Peripheral nerve blockade remains a well-accepted component of comprehensive anaesthetic care due to their distinct advantages over neuraxial and general anaesthesia. Its role has expanded from the operating site into the area of postoperative and chronic pain management. 1 \\ In a new trend of day care surgeries with minimal hospital stay and less financial burden on the patients, brachial plexus block seems to be a better alternative to general anaesthesia.}

Financial or Other, Competing Interest: None.

Submission 24-04-2017, Peer Review 24-05-2017,

Acceptance 31-05-2017, Published 05-06-2017.

Corresponding Author:

Loganathan $S$,

Senior Assistant Professor,

Government Theni Medical College,

Theni, Tamilnadu.

E-mail: dmctheni@gmail.com

DOI: $10.14260 /$ jemds $/ 2017 / 765$

(c) $(7)$
Peripheral nerve block of upper limb includes the various techniques of brachial plexus block. Among brachial plexus blocks, interscalene, supraclavicular and axillary blocks have been routinely used for many years in all over the world. Infraclavicular block has gained interest in recent times.

Infraclavicular brachial plexus block provides anaesthesia for surgery on the distal arm, elbow, forearm, wrist and hand. ${ }^{2,3}$ Numerous modifications of this technique have been developed to improve the success rate and risk of complications. With nerve stimulator, the regional block has advantage of minimal discomfort to patient, lesser chance of nerve damage and improved success rate in contrast to paraesthesia technique. This nerve block targets the musculocutaneous and axillary nerves at the level of the cords before these nerves leave the brachial plexus "sheath". ${ }^{4}$ This block carries no risk of accidental intrathecal, epidural, intravertebral injection, stellate ganglion block or paralysis of hemidiaphragm. Infraclavicular block is often performed by localising one cord within the brachial plexus sheath and 
placing all the local anaesthetic solution at this location. However, success rate of block depends upon the distal twitching of muscles rather than proximal stimulation, also success rate depends on stimulating the cords of the brachial plexus.

\section{Aim of the Study}

To compare the effectiveness of block by stimulating posterior cord with medial cord in infraclavicular block for forearm and hand surgeries by using a nerve stimulator.

\section{Primary Objective}

To assess the effectiveness of upper limb block based on

1. Number of patients reaching the sensory block in the areas distributed by radial, median, ulnar and musculocutaneous nerves.

2. Number of patients with the complete motor block at the level of elbow, hand grip, wrist.

3. Number of patients with complete sensory block.

4. Number of patients with effective upper limb blockade.

5. Number of patients with effectiveness of surgical block.

\section{Secondary Objective}

To assess the complications

1. Subclavian vessel puncture.

2. Local anaesthetic toxicity.

3. Pneumothorax.

\section{MATERIALS AND METHODS}

This was a randomised control trial conducted at Government Theni Medical College Hospital, Theni. Sixty-two patients of ASA grade I or II of either sex undergoing surgery on the elbow, forearm or hand (mostly orthopaedic and plastic surgeries) were randomly allocated into two groups $\mathrm{P}$ and $\mathrm{M}$ using randomly permuted blocks and an online software (http:/www.randomization.com). Each group comprises of 31 patients. Total sample size was 62 and sample size was conveniently taken. Surgery was done under infraclavicular block with posterior cord stimulation-Group $\mathrm{P}$ and medial cord stimulation-Group M.

\section{Exclusion Criteria}

- Hypersensitivity to local anaesthetics.

- Skin infection at the site of puncture.

- Coagulopathy.

- Severe cardiac diseases.

- Neuromuscular disorders.

- Neurological disorders or deficits.

- Pregnancy.

- Any other conditions that requires General Anaesthesia.

\section{Procedure}

Written informed consent will be obtained on the day of surgery. Patients with an average age of 18-60 years undergoing forearm and hand surgeries were randomised into posterior cord (P group) and medial cord group (M group) using computer generated random number method into two groups of 31 each.

Patient was premedicated with tablet Diazepam 0.03 $\mathrm{mg} / \mathrm{kg} 30 \mathrm{~min}$. prior to block procedure. $18 \mathrm{G} \mathrm{IV}$ cannula started on non-surgical limb. Monitors such as pulse oximetry, NIBP and ECG were connected.
Patient was placed in a supine position with head slightly turned to an opposite side and the arm abducted. The coracoid process was palpated and a point $2 \mathrm{~cm}$ medial and $2 \mathrm{~cm}$ inferior to the process identified and marked.5,6 The skin was prepared with chlorhexidine in alcohol solution and the skin overlying this point was infiltrated with $1 \mathrm{~mL}$ of $2 \%$ lignocaine. A $10 \mathrm{~cm}$ long short bevelled insulated needle connected to nerve stimulator is then inserted perpendicular to the skin.7,8 The stimulator was set to deliver rectangular current impulses with a frequency of $2 \mathrm{~Hz}$ and a pulse width of $100 \mathrm{~ms} .^{9}$ The initial stimulating current was set at $1 \mathrm{~mA}$. Once the proximity to cord is identified by visible contractions of an appropriate muscle group the current was incrementally reduced to $0.3 \mathrm{~mA}$ until muscle activity is resumed. If the stimulation persists even with current less than to $0.2 \mathrm{~mA}$ it indicates the needle touches the nerve and there would be more chance for nerve injury, so needle will be withdrawn a little. The cord is identified with specific muscle response. ${ }^{10}$

\section{Medial Cord}

Flexion of fingers, wrist and ulnar deviation of the wrist. 0.5 $\mathrm{mL} / \mathrm{kg}$ of local anaesthetic mixture containing $0.25 \%$ bupivacaine and $2 \%$ lignocaine with adrenaline is injected (not exceeding $30 \mathrm{~mL}$ ) after negative aspiration of blood at the site after electrical stimulation of cord with respect to specific muscle contraction. ${ }^{11,12}$ The block was evaluated for motor and sensory functions serially at 5, 10, 15, 20, 25 and $30 \mathrm{~min}$. For motor block evaluation, the motor activity was observed in elbow, wrist and hand grip. Motor block grading was performed using the following scale-

- Grade 0 - Normal contraction.

- Grade 1 - Reduced contraction or paresis.

- Grade 2 - Complete paralysis.

For sensory block evaluation, patient's skin in the sensory areas of radial, ulnar nerve, median nerve and musculocutaneous nerve were tested with pinprick stimulation. The sensory score for effectiveness of block is documented as-

- Score 2 - Anaesthesia.

- Score 1 - Analgesia.

- Score 0 - Unbearable pain.

Complete sensory block-defined as a sensory block of score 2 in all four nerve territories.

Complete motor block-defined as a motor block of score 2 in all the three joints.

Effectiveness of block-defined as complete sensory block (Score 2 in all four nerve territories) and complete motor block (Score 2 in all above mentioned three joints).

Surgical block-defined as a sensory score of 1 (Analgesia) or score 2 (Anaesthesia) in all four nerve territories after 30 minutes of block irrespective of motor block.

Patients were declared ready for surgery when they has an effective surgical block intraoperatively patients with score 1 of sensory block was given additional dose of $0.25 \mathrm{mg} / \mathrm{kg}$ inj. midazolam and $2 \mu / \mathrm{kg}$ of inj. fentanyl.

All patients were supplemented with nasal oxygen 3-4 L/min. through face mask intraoperatively.

Any complication including bleeding from subclavian vessel puncture, pneumothorax, local anaesthetic toxicity was resolved. At 30 min. after block placement, any patient with 
block that was inadequate for surgery was offered general anaesthesia.

Intra-op haemodynamic monitoring such as heart rate, $\mathrm{BP}$, SPO2 should be measured every $10 \mathrm{~min}$. At the end of the procedure, patient will be transferred to post anaesthesia care unit for observation for $24 \mathrm{hrs}$.

The collected data was analysed with SPSS 16.0 version. To describe about the data descriptive statistics frequency analysis, percentage analysis were used for categorical variables and for continuous variables the mean and S.D. were used. To find the significance difference between the bivariate samples in Independent groups (Types of Surgery) Independent $t$ test was used. To find the significance in categorical data Chi-Square test was used. In all the above statistical tools the probability value 0.05 is considered as significant.

\section{RESULTS}

The age, weight, gender, duration of surgery, surgical distribution were not significantly different and the demographic profile was comparable between two groups.

\begin{tabular}{|c|c|c|c|}
\hline $\begin{array}{c}\text { Patient } \\
\text { Characteristics }\end{array}$ & Group - P & Group - M & $\begin{array}{c}\text { P - } \\
\text { Value }\end{array}$ \\
\hline $\begin{array}{c}\text { Age (years) } \\
\text { Mean } \pm \text { SD }\end{array}$ & $33.45 \pm 12.2$ & $33.19 \pm 12.5$ & 0.935 \\
\hline $\begin{array}{c}\text { Gender } \\
\text { Male:Female }\end{array}$ & $23: 8$ & $25: 6$ & 0.544 \\
\hline $\begin{array}{c}\text { Weight (kg) } \\
\text { Mean } \pm \text { SD }\end{array}$ & $62.87 \pm 7.86$ & $61.87 \pm 6.56$ & 0.588 \\
\hline $\begin{array}{c}\text { Duration of surgery } \\
\text { Mean } \pm \text { SD }\end{array}$ & $66.21 \pm 36.22$ & $67.10 \pm 36.66$ & 0.958 \\
\hline $\begin{array}{c}\text { Surgical distribution } \\
(\%)\end{array}$ \\
$\begin{array}{c}\text { Forearm: Hand: } \\
\text { Forearm \& Hand }\end{array}$ & $48.4: 45.2: 6.5$ & $38.7: 41.9: 19.4$ & 0.306 \\
\hline Table 1. Demographic \& Other Basic Data of the Patients \\
\hline
\end{tabular}

\section{Sensory Block- Ulnar Nerve}

Sensory block in ulnar nerve with score 2 in posterior cord group was $83.9 \%$ and in medial cord group was $87.1 \%$. Sensory block with score 1 in posterior cord group was $16.1 \%$ and in medial cord group was $12.9 \%$. On analysis, the $\mathrm{P}$ value shows 0.718 , hence it is statistically insignificant between two groups.

\section{Sensory Block- Median Nerve}

Sensory block in median nerve distribution with score 2 in posterior cord stimulation was $83.9 \%$ and in medial cord stimulation was $87.1 \%$. Sensory block with 1 in posterior cord stimulation was $16.1 \%$ and medial cord stimulation was $12.9 \%$. On analysis, the $\mathrm{P}$ value shows 0.718 , hence it is statistically insignificant between two groups.

\section{Sensory Block- Musculocutaneous Nerve}

Sensory block with score 2 in posterior cord stimulation was $96.8 \%$ and in medial cord stimulation was $51.6 \%$. Sensory block with score 1 in posterior cord stimulation was $3.2 \%$ and in medial cord stimulation was $45.2 \%$. On analysis, the $P$ value shows 0.001 , hence it is statistically significant between two groups.

\section{Sensory Block-Radial Nerve}

At radial nerve distribution, Sensory score of score 2 is found in 31 patients which is $100 \%$ in group P. In group M 15 patients has score 2 which is $48.4 \%$. Sensory score of 1 is found in 16 patients from Group M. Incomplete block of sensory score 0 is found in one patient from Group M. On analysis, the $P$ value shows .001 which is statistically significant between two groups.

\begin{tabular}{|c|c|c|c|c|c|c|c|c|}
\hline \begin{tabular}{|c|} 
Sensory \\
Block
\end{tabular} & \multicolumn{2}{|c|}{$\begin{array}{l}\text { Radial } \\
\text { Nerve }\end{array}$} & \multicolumn{2}{|c|}{$\begin{array}{l}\text { Ulnar } \\
\text { Nerve }\end{array}$} & \multicolumn{2}{|c|}{$\begin{array}{c}\text { Median } \\
\text { Nerve }\end{array}$} & \multicolumn{2}{|c|}{\begin{tabular}{|c} 
Musculocutane \\
ous Nerve
\end{tabular}} \\
\hline & GrP & GrM & GrP & GrM & GrP & GrM & GrP & GrM \\
\hline Score 0 & 0 & 1 & 0 & 0 & 0 & 1 & 0 & 1 \\
\hline Score 1 & 0 & 15 & 5 & 4 & 5 & 4 & 1 & 14 \\
\hline Score 2 & 31 & 15 & 26 & 27 & 26 & 27 & 30 & 16 \\
\hline $\begin{array}{c}\text { Chi } \\
\text { square } \\
\text { value }\end{array}$ & \multicolumn{2}{|c|}{21.56} & \multicolumn{2}{|c|}{0.130} & \multicolumn{2}{|c|}{ - } & \multicolumn{2}{|c|}{ - } \\
\hline P value & \multicolumn{2}{|c|}{0.001} & \multicolumn{2}{|c|}{0.718} & \multicolumn{2}{|c|}{0.718} & \multicolumn{2}{|c|}{0.001} \\
\hline
\end{tabular}

\section{Motor Block- At Wrist}

Motor block at wrist in posterior cord group with score 2 i.e. complete paralysis is $93.5 \%$ and in medial cord group is $87.1 \%$. Motor block with score 1 in posterior cord group is $6.5 \%$ and in medial cord group has $12.9 \%$. On analysis, the $\mathrm{p}$ value shows 0.390 . Statistically insignificant between two groups.

\section{Motor Block- At Elbow}

Motor block at elbow with score 2 in posterior cord group is $96.8 \%$ and in medial cord group is $45.2 \%$. Motor block with score 1 in posterior cord group is $3.2 \%$ and medial group is $54.8 \%$. On analysis, the P value shows 0.001 , hence statistically significant between two groups.

\begin{tabular}{|c|c|c|c|c|c|c|}
\hline Motor Block & \multicolumn{2}{|c|}{ Elbow } & \multicolumn{2}{c|}{ Wrist } & \multicolumn{2}{c|}{ Handgrip } \\
\hline & GrP & GrM & GrP & GrM & GrP & GrM \\
\hline Score 0 & 0 & 0 & 2 & 4 & 0 & 0 \\
Score 1 & 1 & 17 & 0 & 0 & 5 & 2 \\
Score 2 & 30 & 14 & 29 & 27 & 26 & 29 \\
\hline P value & \multicolumn{2}{|c|}{0.001} & \multicolumn{2}{c|}{0.390} & \multicolumn{2}{c|}{0.229} \\
\hline Table 3. Motor Block- Elbow, Wrist, Handgrip \\
\hline
\end{tabular}

Complete Sensory Block - Sensory Block in all Four Nerves. In all four nerve distributions, 26 patients in group $\mathrm{P}$ and 11 patients in group $M$ were having sensory block of score 2. On analysis, the $\mathrm{P}$ value shows 0.001 which is statistically significant between two groups.

\begin{tabular}{|c|c|c|c|c|}
\hline \multirow{2}{*}{$\begin{array}{c}\text { Complete Sensory } \\
\text { Block }\end{array}$} & \multicolumn{2}{|c|}{ Group P } & \multicolumn{2}{c|}{ Group M } \\
\cline { 2 - 5 } & No. & \% & No. & \% \\
\hline Score 2 & 26 & 83.9 & 11 & 35.5 \\
\hline P value & \multicolumn{2}{|c|}{0.001 significant } & \\
\hline Table 4. Complete Sensory Block in all 4 Nerves \\
\hline
\end{tabular}

\section{Complete Motor Block in all Three Joints}

In all three joints, complete motor block score of 2 is found in 26 patients of posterior cord group, and 11 patients in medial cord group. On analysis, the $\mathrm{P}$ value shows .001 which is statistically significant between two groups. 


\begin{tabular}{|c|c|c|c|c|}
\hline \multirow{2}{*}{$\begin{array}{c}\text { Complete } \\
\text { Motor Block }\end{array}$} & \multicolumn{2}{|c|}{ Group P } & \multicolumn{2}{c|}{ Group M } \\
\cline { 2 - 5 } & No. & $\mathbf{\%}$ & No. & \% \\
\hline Score 2 & 26 & 83.9 & 11 & 35.5 \\
\hline 'P'Value & 0.001 & & & \\
\hline Table 5. Complete Motor Block in all 3 Joints \\
\hline
\end{tabular}

\begin{tabular}{|c|c|c|c|c|}
\hline \multirow{2}{*}{$\begin{array}{c}\text { Complete Motor and } \\
\text { Sensory Block }\end{array}$} & \multicolumn{2}{|c|}{ Group P } & \multicolumn{2}{c|}{ Group M } \\
\cline { 2 - 5 } & No. & $\%$ & No. & $\%$ \\
\hline Score 2 & 26 & 83.9 & 11 & 35.5 \\
\hline 'P' Value & 0.001 significant & & \\
\hline Table 6. Effectiveness of Complete Motor and Sensory \\
Block
\end{tabular}

\begin{tabular}{|c|c|c|c|c|}
\hline \multirow{2}{*}{ Surgical Block } & \multicolumn{2}{|c|}{ Group P } & \multicolumn{2}{c|}{ Group M } \\
\cline { 2 - 5 } & No. & $\mathbf{\%}$ & No. & \% \\
\hline Score 1 & 5 & 16.9 & 18 & 58.06 \\
\hline 'P' Value & \multicolumn{2}{|c|}{0.002 significant } & & \\
\hline & Table 7. Effectiveness of Surgical Block \\
\hline
\end{tabular}

\begin{tabular}{|c|c|c|c|c|}
\hline \multirow{2}{*}{ Complications } & \multicolumn{2}{|c|}{ Group P } & \multicolumn{2}{c|}{ Group M } \\
\cline { 2 - 5 } & No. & $\mathbf{\%}$ & No. & \% \\
\hline Vessel puncture & 1 & 3.2 & 1 & 3.2 \\
\hline Pneumothorax & 0 & 0 & 0 & 0 \\
\hline $\begin{array}{c}\text { Cardiac/ } \\
\text { Toxic/ } \\
\text { CNS toxic }\end{array}$ & 0 & 0 & 0 & 0 \\
\hline 'P' Value & \multicolumn{3}{|c|}{1.000 not significant } \\
\hline Table 8. Complications between Two Groups
\end{tabular}

\section{DISCUSSION}

\section{Discussion of Demographic Variable}

We included patients in the age group of 18 to 60 years in our study. It is done for two reasons. The paediatric patients have immature nerves and the coverings around the nerve is not well developed so very small quantity of the drug if deposited nearer to the nerve is more than enough to cause complete blockade which is not the situation in normal adults. Hence for these reasons we avoided paediatric age groups. In geriatric age groups problems of age related nerve degeneration and altered sensations may pose problems in arriving at the results.

By statistical analysis of two groups the age distribution between the two groups were statistically not significant with $P$ value of $0.935,(P>0.05)$.

\section{Sex as a Variable}

As like age there were no predilection towards sex between two groups. By statistical analysis of two groups the age distribution between two groups were statistically insignificant with $\mathrm{P}$ value of $0.511,(>0.05)$.

\section{Weight}

When comparing the weight of the patients in two groups it was statistically not significant with a P value of $0.588,(>0.05)$. Surgical distribution between two groups:

On statistical analysis, the surgical distribution between two groups were statistically insignificant with $\mathrm{P}$ value of $0.306,(>0.05)$.

\section{Duration of Surgery between Two Groups}

When comparing the duration of surgery between the two groups it is found be statistically insignificant with the $P$ value of $0.958(>0.05)$.

\section{Outcome Measures}

Various criteria have been used by different authors to determine the success rate of block. A block is considered successful by most authors when analgesia is present in all areas subjected to clinical intervention. This definition is sufficient from a clinical point of view, but implies a falsely high success rate and makes comparison between two groups are difficult. Therefore, to standardise the criteria of success, we considered our block successful when analgesia was present in all areas supplied by the four major nerves.

\section{Sensory Block in all Four Nerve Regions}

The sensory block in four nerve territories radial, ulnar, median and musculocutaneous nerves were compared between the two groups. On analysis, the sensory block is statistically significant between two groups for radial P value 0.00 , musculocutaneous 0.001 and statistically insignificant for median nerve P 0.718 and ulnar nerve P 0.708

Literatures supports our study showing a significant difference between two groups $\mathrm{P}<0.05$ in radial nerve distribution. The reason is radial nerve arises from the posterior cord of brachial plexus and another reason is the anatomical location of plexus in relation to axillary artery, the posterior cord appears to lie central to both the lateral and medial cords and instillation of local anaesthetic at this level will more likely to reach all three cords. Medial cord stimulation has more radial nerve sparing because of its location in relation to artery and proximal spread of local anaesthetic less likely to reach all cords.

\section{Complete Motor Blockade}

In our study, motor block was evaluated at elbow, handgrip and wrist. On analysis between two groups it is found to be statistically significant with $\mathrm{P}$ value 0.001 which is similar to previous studies with a significant $P$ value of 0.002 .

\section{Complete Sensory Block}

Complete sensory block is the sensory score 2 in all four nerve regions radial, ulnar, median and musculocutaneous. In our study on statistical analysis, there is found to be a significant difference between two groups with $\mathrm{P}$ value 0.001 , which supports previous studies with a greater efficacy of sensory blockade with a significant $P$ value of $0.001,0.002$ and 0.03 respectively.

\section{Effectiveness of upper limb blockade i.e. complete motor and sensory-}

Complete motor and sensory block of score 2 in posterior cord group is $83.5 \%$ and in medial cord group is $35.8 \%$. On statistical analysis, there is a significant difference between two groups with $\mathrm{P}$ value 0.001 . According to literature, the location of plexus in relation to axillary artery, in median nerve type response, instillation of local anaesthetic causes superficial spread associated with specific posterior displacement of axillary artery, so less likely to reach all the three cords of the brachial plexus. Injection after radial nerve type or posterior cord stimulation results in more posterior local anaesthetic spread association with medial and upper movement of axillary artery, hence there will be dense block in posterior cord stimulation. 


\section{Surgical Block}

Defined as sensory score of 1 or score 2 in all four nerve territories after 30 minutes of block, irrespective of motor block. In posterior cord group, 5 patients had score 1 and hence posterior cord group patients required supplemental sedation for five patients intraoperatively. In medial cord group, 18 patients required additional sedatives and analgesics intraoperatively. In ultrasound-guided comparison of supraclavicular and infraclavicular block, sensory score of 1 or 2 was considered as a surgical block. 13,14 In our study, similar parameters are used for effectiveness of surgical block. On statistical analysis, the $\mathrm{P}$ value shows 0.002 which is statistically significant between two groups.

Patients with score 1 was given additional sedatives 0.25 $\mathrm{mg} / \mathrm{kg}$ of midazolam and $1 \mathrm{mcg} / \mathrm{kg}$ fentanyl intraoperatively depending upon the surgical area of distribution. In medial cord group, some patients needed intraoperative sedation and analgesics. Two patients from medial cord group had inadequate blockade, score 0 along radial nerve distribution.

\section{Complications}

In both the groups, subclavian vascular puncture was noted in 2 patients while performing the block procedure. No other complications such as pneumothorax, local anaesthetic toxicity have been noted. On analysis, there is statistically insignificant difference between the two groups with a $P$ value 1.000. In a study by Wilsons et al, in coracoid approach of infraclavicular block, subclavian venous puncture was noted.

\section{CONCLUSION}

From our study, it is inferred that nerve stimulator-guided posterior cord stimulation in infraclavicular block through coracoid approach has greatest extent and effectiveness of motor and sensory block when compared to medial cord stimulation with similar rate of complications.

\section{REFERENCES}

[1] Labat G. Brachial plexus block: some details of technique. J Anesth \& Analg 1927;6(2):81-2.

[2] Raj PP, Montgomery SJ, Nettles D, et al. Infraclavicular brachial plexus block-a new approach. J Anesth \& Analg 1973;52(6):897-904.

[3] Kilka HG, Geiger P, Mehrkens HH, et al. Infraclavicular vertical brachial plexus blockade. A new method for anatomical and clinical study. J Anesth \& Analg 1995;44(5):339-44.
[4] Selander D, Dhuner KG, Lundborg G, et al. Peripheral nerve injury due to injection needles used for regional anaesthesia. An experimental study of the acute effects of needle point trauma. J Acta Anaest Scand 1977;21(3):182-8.

[5] Klaastad O, Lilleas FG, Rotnes JS, et al. Magnetic resonance imaging demonstrates lack of precision in needle placement by the infraclavicular brachial plexus block described by Raj et al. J Anesth \& Analg 1999;88(3):593-8.

[6] Lecamwasam H, Mayfield J, Rosow L, et al. Stimulation of the posterior cord predicts successful infraclavicular block. J Anesth Analg 2006;102(5):1564-8.

[7] Kaiser H, Niesel HC, Hans V, et al. Fundamentals and requirements of peripheral electric nerve stimulation. A contribution to the improvement of safety standards for regional anesthesia. J Reg Anesth 1990;13(7):1437.

[8] De Andres J, Sala-Blanch X. Peripheral nerve stimulator in the practice of brachial plexus anesthesia: a review. J Reg Anesth Pain Med 2001;26(5):478-83.

[9] Bowens C, Gupta RK, O'Byrne WT, et al. Selective local anesthetic placement using ultrasound guidance and neurostimulation for infraclavicular brachial plexus block. J Anesth \& Analg 2010;110(5):1480-5.

[10] Sauter AR, Smith HJ, Stubhaug A, et al. Use of magnetic resonant imaging to define the anatomical location closest to all three cords of the infraclavicular brachial plexus. J Anes Analg 2006;103(6):1574-6.

[11] Bloc S, Garnier T, Komly B, et al. Spread of injection associated with radial or median nerve type motor response during infraclavicular brachial plexus block an ultrasound evaluation. J Reg Anaes \& Pain Med 2007;32(2):130-5.

[12] Yang CW, Kwon HU, Cho CK, et al. A comparison of infraclavicular and supraclavicular approaches to the brachial plexus using neurostimulation. Korean J Anesthesia 2010;58(3):260-6.

[13] Rodríguez J, Bárcena M, Taboada-Muñiz M, et al. A comparison of single versus multiple injections on the extent of anesthesia with coracoid infraclavicular brachial plexus block. J Anesth \& Analg 2004;99(4):1225-30.

[14] Ootaki C, Hayashi H, Amano M, et al. Ultrasoundguided infraclavicular brachial plexus block: an alternative technique to anatomical landmark guided approaches. J Reg Anesth \& Pain Med 2000;25(6): 600-4. 